\title{
Immunoreactive $\beta$-Endorphin and Adrenocorticotropin in Human Cerebrospinal Fluid
}

\author{
Kazuwa NakaO, Shogo Oki, Issey Tanaka, Kazuko Horit, Yoshikatsu Nakai, \\ Tomoo Furui, Masanori Fukushima, Akio Kuwayama, NaOki Kageyama, \\ and Hiroo Imura, Second Division, Department of Medicine, Kyoto University, \\ School of Medicine, Kyoto 606; Department of Neurosurgery, Nagoya University, \\ School of Medicine, Nagoya 466; Department of Internal Medicine, \\ Aichi Cancer Center, Nagoya 464, Japan
}

A B S T RACT To elucidate the significance of $\beta$ endorphin in human cerebrospinal fluid (CSF), CSF levels of $\beta$-endorphin-like immunoreactivity ( $\beta$-EP-LI) in various diseases were determined by a specific radioimmunoassay and compared with simultaneously determined ACTH-like immunoreactivity (ACTH-LI) levels in CSF. CSF $\beta$-EP-LI and ACTH-LI in the control group, consisting of 5 normal subjects and 19 patients with nonendocrine diseases, were $22.2 \pm 1.3$ and $14.6 \pm 0.4 \mathrm{fmol} / \mathrm{ml}$, respectively. CSF levels of these peptides in patients with schizophrenia $(n=19)$ and acromegaly $(n=10)$ were not significantly different from those in the control group. Patients with Cushing's disease $(n=7)$ had significantly lower CSF $\beta$-EP-LI and ACTH-LI levels than those in the control group. Four of them showed a parallel increase in CSF $\beta$ EP-LI and CSF ACTH-LI levels after the complete removal of pituitary microadenomas $(P<0.05)$.

Gel chromatography of CSF $\beta$-EP-LI from a normal volunteer, a control patient, and one patient each with catatonia, Nelson's syndrome, Cushing's syndrome (adrenal adenoma), and acromegaly gave similar patterns consisting of three peaks with the elution positions comparable to those of authentic $\beta$-endorphin, $\beta$-lipotropin, and possibly their precursor molecule.

Gel chromatographic patterns of CSF $\beta$-EP-LI and ACTH-LI were compared in a normal volunteer. The first peaks of $\beta$-EP-LI and ACTH-LI eluted at the same position and the second peak of ACTH-LI coincided with the elution position of authentic ACTH.

CSF $\beta$-EP-LI and ACTH-LI levels determined every $5 \mathrm{~min}$ over a period of $80 \mathrm{~min}$ in three normal volunteers did not show moment-to-moment variability.

A significant correlation $(r=0.75, P<0.001)$ was

Received for publication 21 April 1980 and in revised form 4 August 1980. seen between CSF $\beta$-EP-LI and ACTH-LI levels in normal subjects and patients studied $(n=73)$. This suggests that $\beta$-endorphin and ACTH in human CSF share the common regulatory mechanism in normal and pathologic conditions.

\section{INTRODUCTION}

$\beta$-Endorphin, which corresponds to $61-91$ amino acids of $\beta$-lipotropin $\left(\beta\right.$-LPH), ${ }^{1}$ is a potent opioid peptide and has profound effects on mood and behavior (1-3). Since $\beta$-endorphin exists not only in the pituitary but also in the brain (4-9), it has been proposed that schizophrenia is related to dysfunctions in the endorphin system (10). However, the origin of brain $\beta$-endorphin is controversial, and both the pituitary and brain have been postulated as possible sites $(4,9,11)$.

Previous studies have demonstrated that $\beta$-endorphin, distinct from $\beta$-LPH, exists in normal human plasma $(12-14)$ and that it increases in parallel with ACTH after metyrapone administration $(12,13,15)$ or insulin-induced hypoglycemia $(15,16)$. High plasma $\beta$-endorphin levels were observed in patients with Nelson's syndrome, Addison's disease, and Cushing's disease in whom plasma ACTH levels were also elevated $(14,17-19)$. These observations suggest the possible pituitary origin of $\beta$-endorphin in peripheral blood and are consistent with the discovery that $\mathrm{ACTH}, \beta$-LPH, and $\beta$-endorphin are derived from a common precursor molecule in a mouse pituitary cell line AT-20/D-16V (20) and in the bovine pituitary (21).

On the other hand, little is known about hormones in the cerebrospinal fluid (CSF). ACTH-like immuno-

\footnotetext{
'Abbreviations used in this maper: ACTH-LI, ACTH-like immunoreactivity; CSF, cerebrospinal fluid; $\beta$-EP-LI, $\beta$ endorphin-like immunoreactivity; B-LPH, $\beta$-lipotropin; RIA, radioimmunoassay.
} 
reactivity (ACTH-LI) has been demonstrated in human $\operatorname{CSF}(22,23)$ in concentrations which did not correlate with plasma ACTH-LI levels (23). The presence of $\beta$-endorphin-like immunoreactivity ( $\beta$-EP-LI) in human CSF was suggested by the difference between $\beta$-EPLI measured by an antiserum directed towards the $\mathrm{COOH}$-terminal portion of $\beta$-LPH and $\beta$-LPH-like immunoreactivity measured by a $\mathrm{NH}_{2}$-terminal antiserum (24). However, the nature of $\beta$-EP-LI in CSF was not clear because of the cross-reactivity of $\beta$-LPH and $\beta$-endorphin with the $\mathrm{COOH}$-terminal antiserum.

Utilizing a sensitive radioimmunoassay (RIA) for $\beta$-endorphin, combined with gel exclusion chromatography, we have demonstrated that $\beta$-EP-LI in human CSF consists of $\beta$-endorphin, $\beta$-LPH, and possibly the precursor molecule and that there is a marked dissociation between plasma and CSF $\beta$-EP-LI levels (25). However, the relationship between $\beta$ endorphin and ACTH in the CSF is not clear. The present study was designed to clarify the relationship of $\beta$-endorphin and ACTH in human CSF.

\section{METHODS}

\section{Subjects}

Five normal volunteers and 19 patients without endocrine abnormalities (intervertebral disk hernia and cerebrovascular accident), 19 patients with schizophrenia (11 with hebephrenia, 6 with catatonia, 2 with paranoia), 1 with depression, 1 with atypical psychosis, 1 with undifferentiated psychosis, 7 with Cushing's disease, 10 with active acromegaly, 2 with Nelson's syndrome, 1 with Addison's disease, 1 with Cushing's syndrome due to adrenal adenoma, 2 with isolated ACTH deficiency, and 4 under glucocorticoid treatment (prednisolone $15-20 \mathrm{mg} / \mathrm{d}$ ) were studied. The patients with intervertebral disk hernia and those with cerebrovascular accident were studied before medication. The patients with schizophrenia and those with other psychoses had been maintained on the routine dosage of neuroleptic drugs. Five of seven patients with Cushing's disease and one of two patients with Nelson's syndrome were studied both before and after transsphenoidal microsurgery. Four of the five patients with Cushing's disease showed normal urinary excretion of 17-hydroxysteroids and 17-ketosteroids and normal plasma cortisol levels after the adenomectomy. Their clinical manifestations due to Cushing's disease disappeared completely. One patient with Cushing's disease showed no improvement of laboratory findings and clinical manifestations after the operation. One patient with Nelson's syndrome maintained on $30 \mathrm{mg} / \mathrm{d}$ of cortisol showed a remarkable improvement of pigmentation after the operation with a marked diminution of plasma ACTH levels.

Lumbar puncture was performed under local anesthesia at 9:00 a.m. after an overnight fast. None of the subjects complained of pain. CSF was collected into chilled siliconized disposable glass tubes, stored at $-20^{\circ} \mathrm{C}$ and thawed only once at the time of hormone assay.

Blood samples were withdrawn into chilled plastic syringes immediately before lumbar puncture and transferred to chilled siliconized disposable glass tubes containing Trasylol (500 kallikrein inactivator $\mathrm{U} / \mathrm{ml}$ Delbay Pharmaceuticals, Div. of Schering Corp., Bloomfield, N. J.) and EDTA $(1 \mathrm{mg} / \mathrm{ml})$. Plasma was immediately separated by centrifugation in a refrigerated centrifuge, and stored at $-20^{\circ} \mathrm{C}$ until assayed.

For gel exclusion chromatographic studies of CSF $\beta$-EP-LI, $5 \mathrm{ml}$ of CSF from a normal volunteer, and one patient each with cerebrovascular accident, catatonia, Nelson's syndrome, Cushing's syndrome, and acromegaly were immediately divided into $1-\mathrm{ml}$ aliquots and lyophilized. The recovery of human $\beta$-LPH $(5-20 \mathrm{fmol} / \mathrm{ml})$ and human $\beta$-endorphin $(3-12 \mathrm{fmol} / \mathrm{ml}$ ) added to CSF was 80 and $65 \%$, respectively, during the procedure of lyophilization and reconstitution.

To compare chromatographic patterns of both CSF $\beta$-EP-LI and ACTH-LI, $8 \mathrm{ml}$ of CSF from a normal volunteer was divided into 1-ml aliquots and lyophilized.

To clarify the moment-to-moment variability in $\beta$-EP-LI or ACTH-LI levels, lumbar CSF was collected every $5 \mathrm{~min}$ from three normal volunteers over a period of $80 \mathrm{~min}$.

\section{RIA}

RIA for $\beta$-endorphin. RIA for $\beta$-endorphin was performed using the talc adsorption method as described $(26,27)$. The RIA standard diluent consisted of $0.05 \mathrm{M}$ phosphate buffer containing $0.5 \%$ human serum albumin (fraction V, ICN Nutritional Pharmaceuticals, Cleveland, Ohio), 500 kallikrein inactivator $\mathrm{U} / \mathrm{ml}$ of Trasylol (Delbay Pharmaceuticals) and $0.4 \%$ 2-mercaptoethanol (Nakarai Chemicals, Ltd., Kyoto, Japan). A two-stage assay procedure was employed, incubating $0.1 \mathrm{ml}$ of unextracted CSF sample or standard human $\beta$-endorphin, and antiserum (final dilution 1:500,000) in 0.3 $\mathrm{ml}$ of the standard diluent at $4^{\circ} \mathrm{C}$ for a day and then adding ${ }^{125} \mathrm{I}$ - $\beta$-endorphin in $0.1 \mathrm{ml}$ of the standard diluent and incubating for $3 \mathrm{~d}$ at $4^{\circ} \mathrm{C}$. The standard human $\beta$-endorphin and human $\beta$-LPH were donated by Dr. C. H. Li. The minimal detectable quantity of $\beta$-endorphin was $0.3 \mathrm{fmol}$. Human $\beta$-endorphin and $\beta$-LPH equally displaced ${ }^{125}$ I- $\beta$-endorphin from the antiserum when compared on a molar basis.

RIA for ACTH. RIA for ACTH was performed using the talc adsorption method (28). The RIA procedure was identical in all respects to that described in RIA for $\beta$-endorphin, except that ACTH and the antiserum of CEA-IRE-SORIN association ACTH RIA kit (Atomic Energy Laboratory of Biomedical Products, Gif-sur-Yvette, France) (29) were used instead of $\beta$-endorphin and the $\beta$-endorphin antiserum, respectively. The standard ACTH was donated by the National Pituitary Agency. The minimal detectable quantity of ACTH was 0.2 fmol. This antiserum directs toward the midportion of ACTH, since it reacted similarly with $(1-18)$ and (1-24)ACTH, weakly with (18-39)ACTH ( $<1 \%$ on a weight basis) and not with $\alpha$-melanotropin.

\section{Gel exclusion chromatography}

Lyophilized CSF was reconstituted in $0.3 \mathrm{ml}$ of the standard diluent, applied on a $0.7 \times 47-49 \mathrm{~cm}$ column of Bio-Gel P-60 (Bio-Rad Laboratories, Richmond, Calif.), and eluted with the same diluent at $4^{\circ} \mathrm{C}$. The flow rate was $2 \mathrm{ml} / \mathrm{h}$ and the fraction vol was $0.72 \mathrm{ml}$. The column was calibrated with blue dextran as a void volume, unlabeled human $\beta-\mathrm{LPH}$, human $\beta$-endorphin, and human ACTH, and ${ }^{125} \mathrm{I}$ as salt peak. Recoveries of human $\beta$-LPH, human $\beta$-endorphin, and human ACTH applied on the column were $90-100 \%$ in both cases.

\section{Statistical analysis}

The statistical analysis was performed by Student's $t$ test for paired or unpaired data as appropriate. 


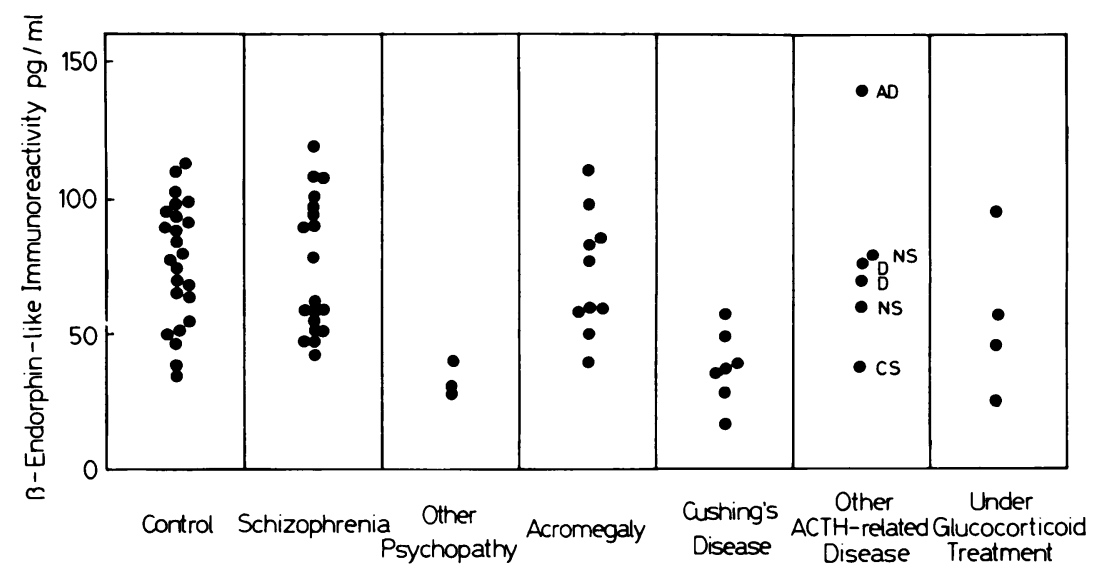

FIGURE $1 \quad \beta$-EP-LI concentrations in CSF from all subjects studied. AD, Addison's disease; NS, Nelson's syndrome; CS, Cushing's syndrome (adrenal adenoma); D, ACTH deficiency.

\section{RESULTS}

Figs. 1 and 2 illustrate CSF $\beta$-EP-LI and ACTH-LI levels in all subjects studied. The mean $( \pm \mathrm{SE})$ hormone levels in each group are shown in Table I. CSF $\beta$-EP-LI and ACTH-LI levels in 5 normal subjects and 19 patients without endocrine abnormalities were not significantly different (Table I). Therefore, all 24 subjects together were included in the control group.

As shown in Table I and Figs. 1 and 2 , CSF $\beta$-EP-LI and ACTH-LI levels in patients with schizophrenia were not significantly different from those in control group. Among the types of schizophrenia, no significant difference was observed in CSF hormone levels, although the levels tended to be higher in catatonia. CSF $\beta$-EP-LI and ACTH-LI levels in patients with active acromegaly were not significantly different from those in the control group. In patients with pituitary-adrenal diseases such as Cushing's disease, Nelson's syndrome, Addison's disease, iso- lated ACTH deficiency, and Cushing's syndrome (adrenal adenoma), those with Cushing's disease showed significantly low CSF $\beta$-EP-LI and ACTH-LI levels, and one with Cushing's syndrome and one with Addison's disease showed low and high $\beta$-EP-LI and ACTH-LI levels, respectively. Two patients with Nelson's syndrome and two patients with isolated ACTH deficiency showed similar values to those in the control group. CSF levels of these hormones in four patients under glucocorticoid treatment were not significantly different from those in the control group, but one of them showed distinctly low CSF hormone levels.

In four of the patients with Cushing's disease, plasma hormone levels were substantially decreased after the complete removal of pituitary microadenoma, but CSF hormone levels were significantly increased $(P<0.05$, Table II). In one patient with Nelson's syndrome the complete removal of the pituitary adenoma had no effect on the CSF hormone levels.

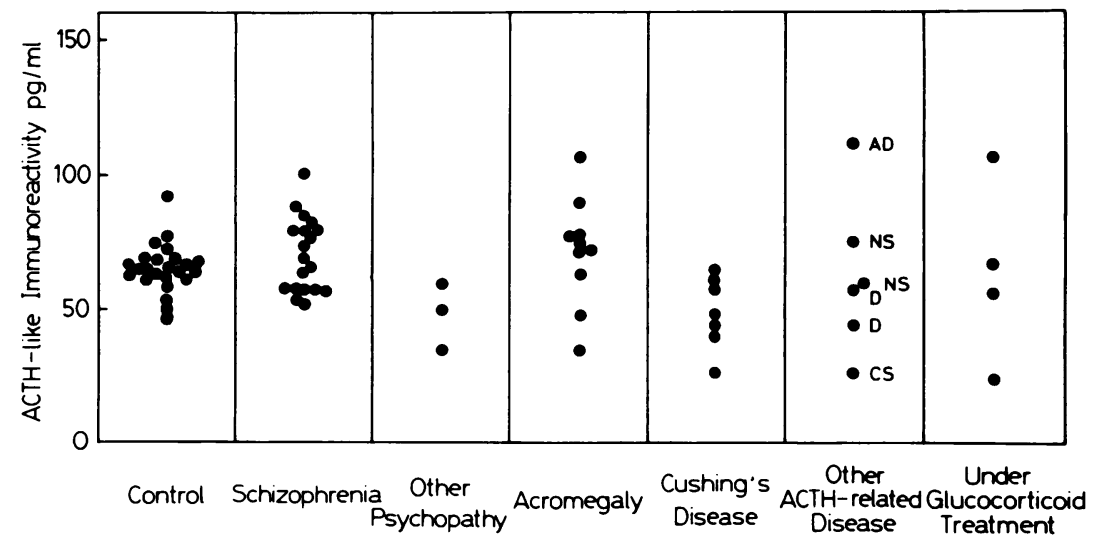

FIGURE 2 ACTH-LI concentrations in CSF from all subjects studied. AD, Addison's disease; NS, Nelson's syndrome; CS, Cushing's syndrome (adrenal adenoma); D, ACTH deficiency. 
TABLE I

$\beta-E P-L I$ and ACTH-LI Levels in Human CSF

\begin{tabular}{lrcc}
\hline & $n$ & $\beta$-EP-LI & ACTH-LI \\
\hline & & $f m o l / m l$ & $f m o l / m l$ \\
Control & 24 & $22.2 \pm 1.3$ & $14.6 \pm 0.4$ \\
$\quad$ Normal & 5 & $22.3 \pm 1.1$ & $14.4 \pm 0.3$ \\
$\quad$ Nonendocrine patients & 19 & $22.1 \pm 1.6$ & $14.6 \pm 0.5$ \\
Schizophrenia & 19 & $22.2 \pm 1.6$ & $15.7 \pm 0.7$ \\
$\quad$ Catatonia & 6 & $26.3 \pm 3.0$ & $17.4 \pm 1.4$ \\
$\quad$ Hebephrenia & 11 & $21.5 \pm 1.7$ & $14.7 \pm 0.8$ \\
$\quad$ Paranoia & 2 & $14.3 \pm 1.8$ & $13.0 \pm 0.1$ \\
Acromegaly & 10 & $21.1 \pm 2.0$ & $15.9 \pm 1.4$ \\
Cushing's disease & 7 & $11.0 \pm 1.5^{*}$ & $10.9 \pm 1.1^{*}$ \\
Patients under glucocorticoid & & & \\
$\quad$ treatment & 4 & $16.4 \pm 4.3$ & $14.2 \pm 3.8$ \\
& & & \\
\hline
\end{tabular}

$* P<0.01$.

In the 73 subjects studied, there was a positive correlation between CSF $\beta$-EP-LI and ACTH-LI levels $(r=0.75, P<0.001$, Fig. 3). A significant correlation between CSF $\beta$-EP-LI and ACTH-LI levels was also observed in each group such as control, schizophrenia, acromegaly, Cushing's disease, and other pituitary-adrenal diseases.

There were no significant fluctuations of CSF $\beta$-EP-LI and ACTH-LI levels studied by sampling every $5 \mathrm{~min}$ over a period of $80 \mathrm{~min}$ in three normal volunteers.

The elution profiles obtained by gel filtration of CSF $\beta$-EP-LI from patients with various diseases are shown in Fig. 4. $\beta$-EP-LI in CSF consisted of two components with elution positions compatible with those of $\beta$-LPH and $\beta$-endorphin, respectively, and one additional component with a larger molecular weight. Similar gel-filtration patterns were observed in six CSF samples from a normal volunteer, one patient each with cerebrovascular accident, catatonia, Nelson's syndrome, Cushing's syndrome (adrenal adenoma), and acromegaly.

The elution profiles obtained by gel filtration of CSF $\beta$-EP-LI and ACTH-LI from a normal volunteer are shown in Fig. 5. ACTH-LI in CSF consisted of three major components, and the second peak eluted in the position compatible for authentic human ACTH. The first peak of CSF ACTH-LI near the void volume co-eluted with that of CSF $\beta$-EP-LI. One additional peak of CSF ACTH-LI was observed in the elution position compatible for the molecule of the size between authentic ACTH and ${ }^{125}$ I.

\section{DISCUSSION}

This study demonstrated that CSF $\beta$-EP-LI and ACTH-LI levels in control subjects were $22.2 \pm 1.3$ and $14.6 \pm 0.4 \mathrm{fmol} / \mathrm{ml}$, respectively. These results are comparable to previously reported values of CSF $\beta$-EP-LI $(24,25)$ and ACTH-LI (23). In addition, a significant positive correlation was observed between $\beta$-EP-LI and ACTH-LI in CSF in normal subjects and patients with various diseases. These results suggest that $\beta$-EP-LI and ACTH-LI in human CSF are regulated by common mechanisms.

The origin of $\beta$-EP-LI and ACTH-LI in CSF is not clear at present. It has been demonstrated that $\beta$ endorphin and ACTH in plasma do not penetrate the blood-CSF barrier $(23,25)$. The analgesic electrical stimulation of periventricular gray matter is known to increase CSF $\beta$-EP-LI levels (30, 31). It is highly likely,

TABLE II

B-EP-LI and ACTH-LI Levels of CSF and Plasma in Cushing's Disease and Nelson's Syndrome before and after the Pituitary Adenomectomy

\begin{tabular}{|c|c|c|c|c|c|c|c|c|c|c|c|c|}
\hline \multirow[b]{3}{*}{ No. } & \multirow[b]{3}{*}{ Case } & \multirow[b]{3}{*}{ Age } & \multirow[b]{3}{*}{ Sex } & \multirow{3}{*}{$\begin{array}{l}\text { Adeno- } \\
\text { mectomy }\end{array}$} & \multicolumn{4}{|c|}{$\beta$-EP-LI } & \multicolumn{4}{|c|}{ ACTH-LI } \\
\hline & & & & & \multicolumn{2}{|c|}{ Before } & \multicolumn{2}{|c|}{ After } & \multicolumn{2}{|c|}{ Before } & \multicolumn{2}{|c|}{ After } \\
\hline & & & & & CSF & Plasma & CSF & Plasma & CSF & Plasma & CSF & Plasma \\
\hline & & & & & \multicolumn{4}{|c|}{$\mathrm{fmol} / \mathrm{ml}$} & \multicolumn{4}{|c|}{$\mathrm{fmol} / \mathrm{ml}$} \\
\hline \multicolumn{13}{|c|}{$\begin{array}{r}\text { Cushing's } \\
\text { disease }\end{array}$} \\
\hline 1 & H.K. & 22 & $\mathbf{M}$ & C & 10.2 & 33.3 & 19.7 & 7.7 & 10.8 & 24.4 & 17.2 & 6.9 \\
\hline 2 & K.T. & 25 & $\mathbf{F}$ & C & 11.4 & 32.9 & 19.2 & $<6.0$ & 10.0 & 34.8 & 16.4 & $<5.6$ \\
\hline 3 & E.F. & 49 & $\mathbf{F}$ & C & 4.9 & 24.6 & 8.1 & $<6.0$ & 6.0 & 24.4 & 7.4 & 6.8 \\
\hline 4 & Y.Y. & 22 & $\mathbf{M}$ & C & 10.9 & 74.5 & 25.2 & 21.8 & 12.8 & 38.4 & 22.1 & $<5.6$ \\
\hline 5 & H. K. & 24 & $\mathbf{M}$ & I & 14.5 & 27.0 & 10.3 & 29.8 & 13.7 & 17.8 & 7.3 & 18.7 \\
\hline & Mean \pm SE & & & & $9.4 \pm 1.5$ & $41.3 \pm 11.2$ & $18.0 \pm 3.6^{*}$ & & $9.9 \pm 1.4$ & $30.5 \pm 3.6$ & $15.8 \pm 3.1^{*}$ & \\
\hline \multicolumn{13}{|c|}{$\begin{array}{l}\text { Nelson's } \\
\text { syndrome }\end{array}$} \\
\hline 6 & Y.A. & 43 & $\mathbf{F}$ & C & 23.1 & 1370 & 20.6 & 52.3 & 16.0 & 1100 & 16.6 & 43.3 \\
\hline
\end{tabular}

Abbreviations used in this table: M, male; F, female; C, complete; I, incomplete. $* P<0.05$. 


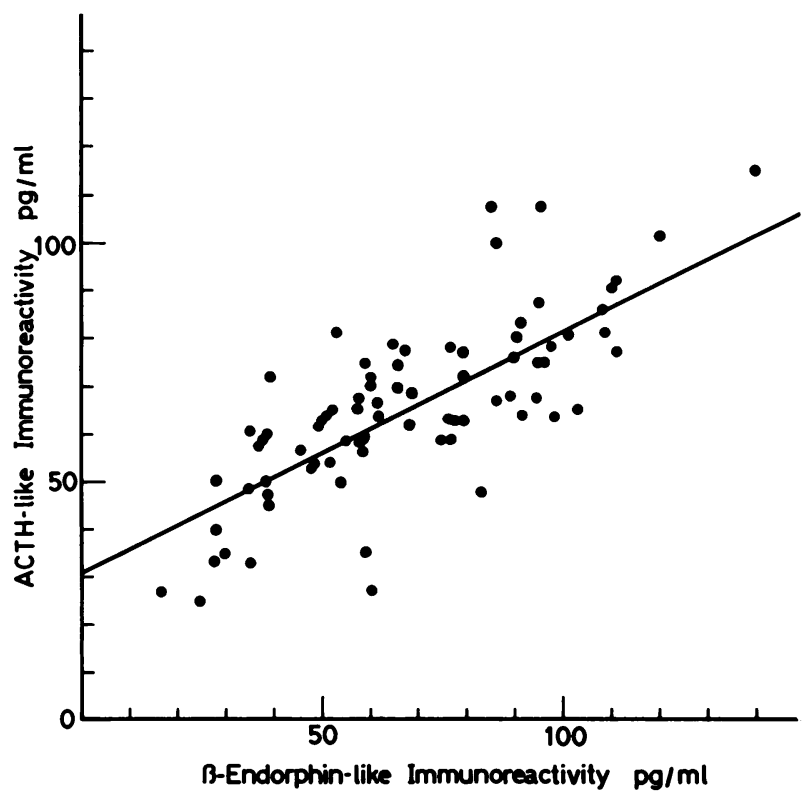

FIGURE 3 Correlation between $\beta$-EP-LI and ACTH-LI concentrations in $73 \mathrm{CSF}$ samples. A significant positive correlation was observed between them $(r=0.75, P<0.001)$.

therefore, that $\beta$-EP-LI and ACTH-LI in CSF originate from the brain and not from the pituitary or blood. Our previous observation that plasma and CSF $\beta$ endorphin levels can be dissociated under pathological conditions (25) also supports the central nervous system origin of CSF $\beta$-endorphin and ACTH. Recent studies by Liotta et al. (11) have shown that a common molecule of $\beta$-endorphin and ACTH with a high molecular weight is synthesized by cultured bovine hypothalamic cells. Our present study also demonstrated the presence of $\beta$-EP-LI and ACTH-LI of a high molecular weight form, which was eluted on gel chromatography at the elution position of the common precursor molecule.

Another interesting finding in this study is the noticeable changes of $\beta$-EP-LI and ACTH-LI levels in plasma and CSF in Cushing's disease before and after the operation. Both CSF $\beta$-EP-LI and ACTH-LI levels in Cushing's disease before the surgery were significantly lower than those in the control group, although plasma levels were significantly higher in Cushing's disease than those in the control group. Plasma $\beta$-EP-LI and ACTH-LI levels were substantially decreased after the complete removal of the microadenomas, but their CSF levels were increased conversely after the operation. These findings clearly demonstrate a concomitant change of $\beta$-EP-LI and ACTH-LI levels in human CSF and strongly suggest the presence of common regulatory mechanisms. However, the cause of low CSF levels of these peptides in cases of Cushing's disease is not clear at present. This abnormality might be caused by overproduced glucocorticoid, and not by ACTH or $\beta$ endorphin, because CSF hormone levels were low in a patient with Cushing's syndrome due to adrenal

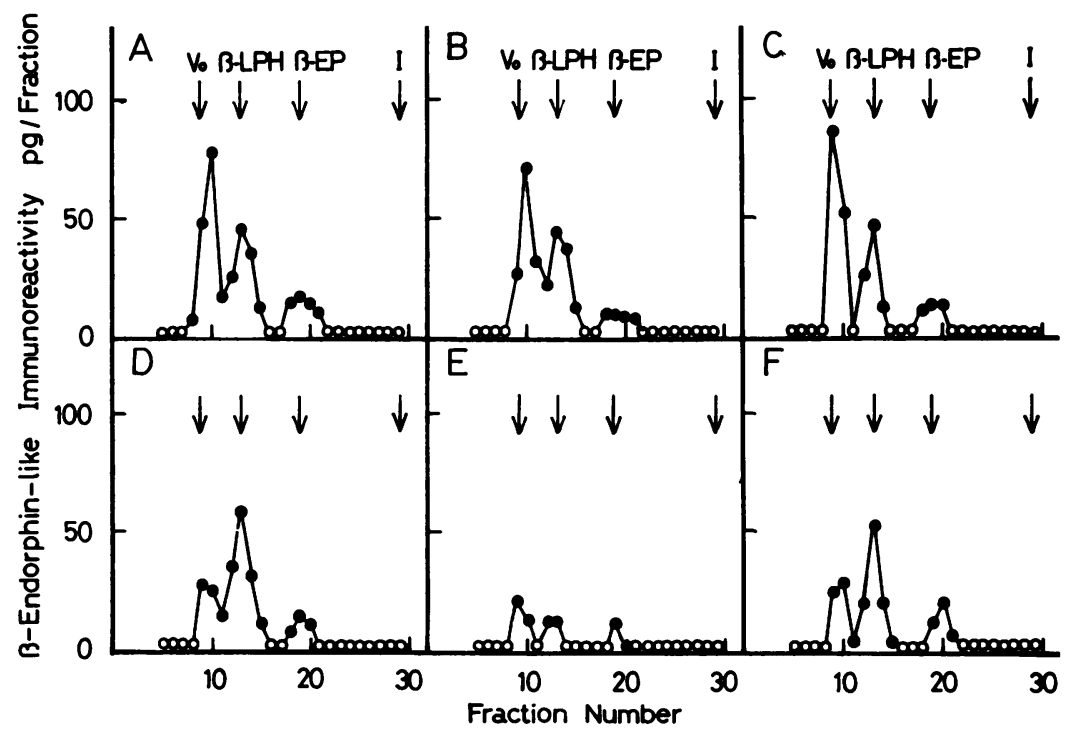

Figure 4 Elution profiles obtained by gel-filtration (Bio-Gel P-60, $0.7 \times 49 \mathrm{~cm}$ ) of six CSF samples. The lyophilized CSF was reconstituted in $0.3 \mathrm{ml}$ standard diluent and $0.25 \mathrm{ml}$ of reconstituted solution was applied to the column. The fractions were assayed by RIA for $\beta$-endorphin. A, normal volunteer; B, cerebrovascular accident; C, schizophrenia (catatonia); D, Nelson's syndrome; E, Cushing's syndrome (adrenal adenoma); F, acromegaly. Vo, void volume; I, iodine. 


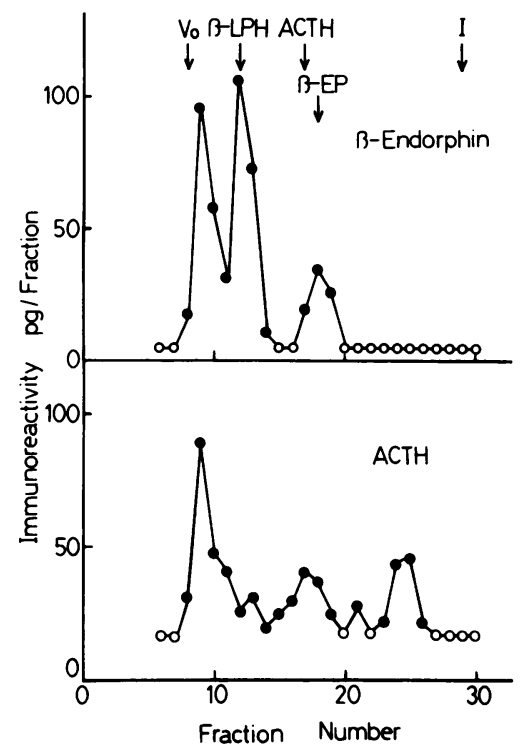

Figure 5 Elution profiles obtained by gel-filtration (BioGel P-60, $0.7 \times 47 \mathrm{~cm}$ ) of CSF from a normal volunteer. The lyophilized CSF was reconstituted in a $0.3 \mathrm{ml}$ of standard diluent and $0.25 \mathrm{ml}$ of the reconstituted solution was applied to the column. The fractions were analyzed in two systems of RIA: $\beta$-endorphin and ACTH. Vo, void volume; I, iodine.

adenoma, high in a patient with Addison's disease, and within normal limits in two patients with Nelson's syndrome who were maintained on steroids. In addition, CSF $\beta$-EP-LI and ACTH-LI levels were unchanged in a patient with Nelson's syndrome even after the complete removal of the pituitary adenoma, although plasma levels of these hormones were remarkably decreased (T.A. in Table II). However, CSF levels of these hormones in four patients under glucocorticoid treatment were not significantly different from those in the control group, and only one of them showed distinctly low CSF hormone levels. The discrepancy between CSF levels in patients with Cushing's disease and those under glucocorticoid treatment may be explained by the dose of glucocorticoid, because the remaining three patients had received only a single dose of prednisolone $(15 \mathrm{mg})$ in the morning. It is also possible that other still unknown factors may cause the low CSF $\beta$-EP-LI and ACTH-LI levels in patients with Cushing's disease.

The present study also demonstrates that there is no episodic change in $\beta$-EP-LI and ACTH-LI levels in human CSF because 5-min sampling over a period of $80 \mathrm{~min}$ disclosed little moment-to-moment variability. The results also suggest that the effect of lumbar puncture on $\beta$-EP-LI and ACTH-LI levels in CSF, if any, is minimal.

A hypothesis that schizophrenia is caused by dysfunction of the endorphin system has been proposed
(10) because $\beta$-endorphin injected intraventricularly induced catatonia in rats (32) and because naloxone, an opiate receptor antagonist, is reported to reduce auditory hallucination in schizophrenia $(33,34)$. This study shows that CSF $\beta$-EP-LI levels in schizophrenia do not differ from those in the controls and that a gel chromatographic pattern of CSF $\beta$-EP-LI from a catatoniac is essentially similar to that of a normal volunteer and to those of other patients. These results are in disagreement with preliminary findings of Domschke et al. (35), who reported levels of CSF $\beta$-EP-LI about 10 times higher in acute paranoid patients and two times lower in chronic schizophrenia than of the control group. Reason for the discrepancy of the results may be explained in part by the difference in phase and medication of schizophrenia. However, our study shows a correlation between CSF $\beta$-EP-LI and ACTH-LI levels in schizophrenia, and therefore excludes technical errors, although Domschke et al. did not report CSF ACTH-LI levels. Recently it has been reported that plasma $\beta$-EP-LI levels in schizophrenia do not differ from those in controls (36) and that intraventricular administration of $\beta$-endorphin produced no psychiatric symptoms in patients (37). Moreover, contradictory results have been reported regarding the effect of naloxone on symptoms in schizophrenia (38-41). It seems necessary, therefore, to reevaluate involvement of $\beta$-endorphin in schizophrenia.

CSF $\beta$-EP-LI and ACTH-LI levels in acromegaly are of interest, because intraventricular administration of $\beta$-endorphin stimulates growth hormone secretion in animals (42). In this study, however, CSF $\beta$-EP-LI and ACTH-LI levels in acromegaly did not differ from those in the control group and the gel chromatographic pattern of CSF $\beta$-EP-LI from a patient with acromegaly was similar to those of other subjects. Thus, our results are in disagreement with those of Wiedemann et al. $(43,44)$, who reported elevated CSF concentration of $\beta$-EP-LI in acromegaly. The reason for this discrepancy is not clear. It should be noted, however, that a significant positive correlation was demonstrated between CSF $\beta$-EP-LI and ACTH-LI levels in acromegaly and that CSF ACTH-LI levels in this study are in agreement with those of Allen et al. (23).

Recently, Zakarian and Smyth (45) reported that immunoreactive $\beta$-endorphin demonstrated on gel exclusion chromatography consists of $\mathrm{C}$ fragment (61-91 of $\beta$-LPH), $C^{\prime}$ fragment (61-87) and their $\mathrm{N}$-acetylated forms and that the processing of lipotropin is under different control in anatomically distinct regions in rat pituitary and brain. Their group also reported that $\mathrm{C}$ fragment, $\mathrm{C}^{\prime}$ fragment and their $\mathrm{N}$ acetylated forms were isolated from porcine pituitary (46). However, active and inactive forms of endorphins in human pituitary and brain are not clear at present. The physiological significance and the nature of 
$\beta$-EP-LI in human cerebrospinal fluid must await further investigation.

\section{ACKNOWLEDGMENTS}

We are indebted to Professor Choh $\mathrm{Hao} \mathrm{Li}$, Hormone Research Laboratory, University of California, San Francisco, for the generous supply of human $\beta$-endorphin and human $\beta$ lipotropin; to the hormone distribution program, National Institute of Arthritis, Metabolism, and Digestive Diseases, National Pituitary Agency for the generous supply of standard ACTH; to Doctors T. Kitade and M. Hyodo, Department of Anesthesiology, Osaka Medical College, Ibaragi, Osaka; to Doctors M. Nakura, O. Hayashi, A. Higashimura, and S. Miyoshi, Department of Psychiatry, Aino Hospital, Ibaragi, Osaka; and to Doctors T. Konishi, H. Nishitani, Department of Neurology, National Utano Hospital, Kyoto, Japan who provided samples for our study. We also thank Mr. H. Arai for technical assistance, Miss Y. Mitsuda and Miss C. Tamura for secretarial assistance, and Miss M. Ohara for comments on the manuscript.

This work was supported in part by research grants for "Specific Diseases" from the Japanese Ministry of Health and Welfare and from the Ministry of Education, Science and Culture.

\section{REFERENCES}

1. Loh, H. H., L. F. Tsueng, E. Wei, and C. H. Li. 1976 $\beta$-Endorphin is a potent analgesic agent. Proc. Natl. Acad. Sci. U. S. A. 73: 2895-2898.

2. Lazarus, L. H., N. Ling, and R. Guillemin. 1976. $\beta$-Lipotropin as a prohormone for the morphinomimetric peptides endorphins and enkephalins. Proc. Natl. Acad. Sci. U. S. A. 73: 2156-2159.

3. Meglio, M., Y. Hosobuchi, H. H. Loh, J. E. Adams, and C. H. Li. 1977. $\beta$-Endophin: Behavioral and analgesic activity in cats. Proc. Natl. Acad. Sci.U.S.A. 74: 774-776.

4. Rossier, J., T. M. Vargo, S. Minick, N. Ling, F. E. Bloom, and R. Guillemin. 1977. Regional dissociation of $\beta$ endorphin and enkephalin contents in rat brain and pituitary. Proc. Natl. Acad. Sci. U. S. A. 74: 5162-516.5.

5. Bloom, F., E. Battenberg, J. Rossier, N. Ling, and R. Guillemin. 1978. Neurons containing $\beta$-endorphin in rat brain exist separately from those containing enkephalin: Immunocytochemical studies. Proc. Natl. Acad. Sci. U. S. A. 75: 1591-1595.

6. Watson, S. J., H. Akil, C. W. Richard, and J. D. Barchas. 1978. Evidence for two separate opiate peptide neuronal systems. Nature (Lond.). 275: 226-228.

7. Gramsch, C., V. Hollt, P. Mehraesin, A. Pasi, and A. Herz. 1979. Regional distribution of methionine-enkephalinand beta-endorphin-like immunoreactivity in human brain and pituitary. Brain Res. 171: 261-270.

8. Matsukura, S., H. Yoshimi, S. Sueoka, M. Yokota, T. Ono, and $N$. Ohgushi. 1978. The regional distribution of immunoreactive $\beta$-endorphin in the monkey brain. Brain Res. 159, 228-233.

9. Ogawa, N., A. E. Panerai, S. Lee, G. Forsbach, V. Hatlicek, and H. G. Friesen. 1979. $\beta$-Endorphin concentration in the brain of intact and hypophysectomized rats. Life Sci. 25: 317-326.

10. Watson, S. J., H. Akil, P. A. Berger, and J. D. Barchas. 1979. Some observations on the opiate peptides and schizophrenia. Arch. Gen. Psychiatry 36: 35-41.

11. Liotta, A., D. Gildersleeve, M. J. Brownstein, and D. T. Krieger. 1979. Biosynthesis in vitro of immunoreactive 31,000-dalton corticotropin/ $\beta$-endorphin-like material by bovine hypothalamus. Proc. Natl. Acad. Sci. U. S. A. 76 : $1448-1452$.

12. Nakao, K., Y. Nakai, S. Oki, K. Horii, and H. Imura. 1978. Presence of immunoreactive $\beta$-endorphin in normal human plasma. A concomitant release of $\beta$-endorphin with adrenocorticotropin after metyrapone administration. J. Clin. Invest. 62: 1395-1398.

13. Wardlaw, S. L., and A. G. Franz. 1979. Measurement of $\beta$-endorphin in human plasma. J. Clin. Endocrinol. Metab. 48: 176-180.

14. Hollt, V., A. Muller, and R. Fahlbusch. 1979. $\beta$-Endorphin in human plasma: basal and pathologically elevated levels. Life Sci. 25: 37-44.

15. Wiedemann, E., T. Saito, J. A. Linfoot, and C. H. Li. 1979. Specific radioimmunoassay of human $\beta$-endorphin in unextracted plasma. J. Clin. Endocrinol. Metab. 49: $478-480$.

16. Nakao, K., Y. Nakai, H. Jingami, S. Oki, J. Fukata, and H. Imura. 1979. Substantial rise of plasma $\beta$-endorphin levels after insulin-induced hypoglycemia in human subjects. J. Clin. Endocrinol. Metab. 49: 838-841.

17. Nakai, Y., K. Nakao, S. Oki, H. Imura, and C. H. Li. 1978. Presence of immunoreactive $\beta$-endorphin in plasma of patients with Nelson's syndrome and Addison's disease. Life Sci. 23: 2293-2298.

18. Suda, T., A. S. Liotta, and D. T. Krieger. 1978. $\beta$-Endorphin is not detectable in plasma from normal human subjects. Science (Wash. D. C.). 202: 221-223.

19. Oki, S., Y. Nakai, K. Nakao, and H. Imura. 1980. Plasma $\beta$-endorphin responses to somatostatin, TRH or vasopressin in Nelson's syndrome.J. Clin. Endocrinol. Metab. 50: $194-196$.

20. Mains, R. E., B. A. Eipper, and N. Ling. 1977. Common precursor to corticotropins and endorphins. Proc. Natl. Acad. Sci. U. S. A. 74: 3014-3018.

21. Nakanishi, S., A. Inoue, S. Taii, and S. Numa. 1977. Cell-free translation product containing corticotorpin and $\beta$-endorphin encoded by messenger RNA from anterior lobe and intermediate lobe of bovine pituitary. FEBS (Fed. Eur. Biochem. Soc.) Lett. 84: 105-109.

22. Kleerekoper, M., R. A. Donald, and S. Posen. 1972. Corticotropin in cerebrospinal fluid patients with Nelson's syndrome. Lancet. I: 74-76.

23. Allen, J. P., J. W. Kendall, R. McGilvra, and C. Vancura. 1974. Immunoreactive ACTH in cerebrospinal fluid. $J$. Clin. Endocrinol. Metab. 38: 586-593.

24. Jeffcoat, W. J., L. H. Rees, L. McLuoghlin, S. J. Ratter, J. Hope, P. J. Lowry, and G. M. Besser. 1978. $\beta$-Endorphin in human cerebrospinal fluid. Lancet. I: 119-121.

25. Nakao, K., Y. Nakai, S. Oki, S. Matsubara, T. Konishi, $H$. Nishitani, and H. Imura. 1980. Immunoreactive $\beta$-endorphin in human cerebrospinal fluid. J. Clin. Endocrinol. Metab. 50: 230-233.

26. Yoshimi, H., S. Matsukura, S. Sueoka, M. Fukase, M Yokota, Y. Hirata, and H. Imura. 1978. Radioimmunoassay for $\beta$-endorphin: presence of immunoreactive "big-big" $\beta$-endorphin ("big" $\beta$-lipotropin) in human and rat pituitaries. Life Sci. 22: 2189-2190.

27. Nakai, Y., K. Nakao, S. Oki, and H. Imura. 1978. Presence of immunoreactive $\beta$-lipotropin and $\beta$-endorphin in human placenta. Life Sci. 23: 2013-2018.

28. Berson, S. A., and R. Yalow. 1968. Radioimmunoassay of ACTH in plasma. J. Clin. Invest. 47: 2725-2751.

29. Vague, P., C. Oliver, P. Jaquet, and J. Vague. 1971. Le dosage radioimmunologique de l'ACTH plasmatique. Resultats chez les sujets normaux. Rev. Eur. Etud. Clin. Biol. 16: 485-493.

30. Akil, H., D. E. Richardson, J. D. Barchas, and C. H. Li. 
1978. Appearance of $\beta$-endorphin-like immunoreactivity in human ventricular cerebrospinal fluid upon analgesic electrical stimulation. Proc. Natl. Acad. Sci. U. S. A. 75: $5170-5172$.

31. Hosobuchi, Y., J. Rossier, F. E. Bloom, and R. Guillemin. 1979. Stimulation of human periaque-ductal gray for pain relief increases immunoreactive $\beta$-endorphin in ventricular fluid. Science (Wash. D. C.). 203: 279-281.

32. Bloom, F., D. Segal, N. Ling, and R. Guillemin. 1976. Endorphins: profound behavioral effects in rats suggest new etiological factors in mental illness. Science (Wash. D. C.). 194: 630-632.

33. Gunne, L. M., L. Lindstrom, and L. Terenius. 1977. Naloxone-induced reversal of schizophrenia hallucinations. J. Neural. Transm. 40: 13-19.

34. Watson, S. J., P. A. Berger, H. Akil, M. J. Mills, and J. D. Barchas. 1978. Effect of naloxone in schizophrenia: reduction in hallucination in a subpopulation of subjects. Science (Wash. D. C.) 201: 73-76.

35. Domschke, W., A. Dickschas, and P. Mitznegg. 1979 C.S.F. $\beta$-endorphin in schizophrenia. Lancet. I: 1024

36. Ross, M., P. A. Berger, and A. Goldstein. 1979. $\beta$-Endorphin immunoreactivity in schizophrenia. Science (Wash. D. C.). 205: 1163-1164.

37. Foley, K. M., I. A. Kourides, C. E. Inturrisi, R. F. Kaiko, C. G. Zaroulis, J. B. Posner, R. W. Houde, and C. H. Li. 1979. $\beta$-Endorphin: Analgesic and hormonal effects in humans. Proc. Natl. Acad. Sci. U. S. A. 76: 5377-5381.

38. Volavka, J., A. Mallya, S. Baig, and Perez-Cruet. 1977. Naloxone in chronic schizophrenia. Science (Wash. D. C.). 196: $1227-1228$
39. Davis, G. C., W. E. Bunney, E. G. DeFraites, J. E. Kleinman, D. P. van Kammen, R. M. Post, and R. J. Wyatt. 1977. Intravenous naloxone administration in schizophrenia and effective illness. Science (Wash. D. C.). 197: 74-77.

40. Kurland, A. A., O. L. MaCable, T. E. Hanlon, and D. Sullivan. 1977. The treatment of perceptual disturbances in schizophrenia with naloxone hydrochloride. Am.J. Psychiatry. 134: 1408-1410.

41. Janowsky, D. S., D. S. Segal, F. Bloom, A. Abrams, and R. Guillemin. 1977. Lack of effect of naloxone on schizophrenic symptoms. Am. J. Psychiatry. 134: 926-927.

42. Kato, Y., Y. Iwasaki, H. Abe, S. Hogo, and H. Imura. 1978. Effects of endorphins on prolactin and growth hormone secretion in rats. Proc. Soc. Exp. Biol. Med. 158: 431-436.

43. Wiedemann, E., T. Saito, J. A. Linfoot, and C. H. Li. 1979. Beta-endorphin and beta-lipotropin in human cerebrospinal fluid. Abstracts of 61st annual meeting of the endocrine society. Anaheim, Calif. Abstr. 224

44. Wiedemann, E., T. Saito, and J. A. Linfoot. 1980. Elevated cerebrospinal fluid $\beta$-endorphin and $\beta$-lipotropin in acromegaly. Abstracts of sixth international congress of endocrinology, Melbourne, No. 249.

45. Zakarian, S., and D. Smyth. 1979. Distribution of active and inactive forms of endorphins in rat pituitary and brain. Proc. Natl. Acad. Sci. U. S. A. 76: 5972-5976.

46. Smyth, D. G., D. E. Massey, S. Zakarian, and M. D. A. Finnie. 1979. Endorphins are stored in biologically active and inactive forms: isolation of $\alpha$-N-acetyl peptides. Nature (Lond.). 279: 252-254. 